\title{
An Agenda for Land-Surface Hydrology Research and a Call for the Second International Hydrological Decade
}

Dara Entekhabi ${ }^{1}$, Ghassem R. Asrar ${ }^{2}$, Alan K. Betts ${ }^{3}$, Keith J. Beven ${ }^{4}$, Rafael L. Bras ${ }^{1}$, Christopher J. Duffy ${ }^{5}$, Thomas Dunne ${ }^{6}$, Randall D. Koster 7 , Dennis P. Lettenmaier ${ }^{8}$, Dennis B. McLaughlin ${ }^{1}$, William J. Shuttleworth' ${ }^{9}$ Martinus T. van Genuchten ${ }^{10}$, MingYing Wei ${ }^{2}$, Eric F. Wood ${ }^{11}$

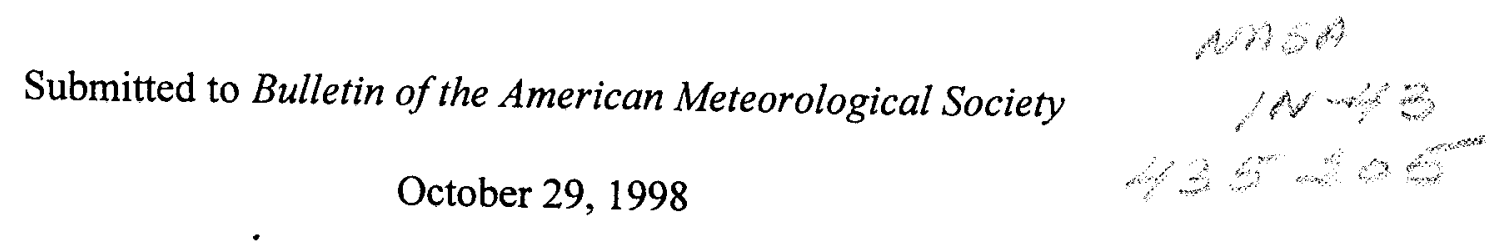

\section{ABSTRACT}

An agenda for land-surface hydrology research is proposed to open the debate for more comprehensive prioritization of science and application activities in the hydrologic sciences. A set of science questions are posed and the observational requirements to achieve substantial progress are identified. In this context, the proposal to initiate the $2^{\text {nd }}$ International Hydrologic Decade (IHD) is put forth. The benefits of this initiative for enhanced scientific understanding and improved capability in meeting societal needs are also identified.

Additional affiliations: 'Massachusetts Institute of Technology, Cambridge, Massachusetts, ${ }^{2}$ National Aeronautics and Space Administration Headquarters, Washington, D.C. ${ }^{3}$ Atmospheric Research, Pittsford, Vermont, ${ }^{4}$ University of Lancaster, Lancaster, Great Britain, ${ }^{5}$ Pennsylvania State University, University Park, Pennsylvania, ${ }^{6}$ University of California at Santa Barbara, Santa Barbara, California, ${ }^{7}$ Goddard Space Flight Center, National Aeronautics and Space Administration, Greenbelt, Maryland, ${ }^{8}$ University of Washington, Seattle, Washington, ${ }^{9}$ University of Arizona, Tucson, Arizona, ${ }^{10}$ U.S. Salinity Laboratory, U.S. Department of Agriculture, Riverside, California, " Princeton University, Princeton, New Jersey

Corresponding author address: Dara Entekhabi, 48-331 M.I.T., Cambridge, MA 02139. darae@MIT.edu. 


\section{Mission}

During the past two decades, land-surface hydrology research has been transformed by shifts in intellectual paradigm and technological advances. The new paradigm couples land-surface hydrology with other components of the Earth system. This coupling is now considered essential. This new thinking has led to significant changes in the research and training foci for the discipline. In this respect, land-surface hydrology demonstrates well and partially fulfills a major recommendation in the National Research Council's Opportunities in the Hydrologic Science report that states: "Hydrologic science should be viewed as a geoscience interactive on a wide range of space and time-scales with the ocean, atmospheric, and solid earth sciences as well as with plant and animal sciences (NRC 1991)." Technological advances in environmental monitoring and remote-sensing have opened new perspectives on land-surface processes. These new observations have made possible applications that could not be based on conventional observing systems. Land-surface hydrology at the start of the new millennium is working with radically new thinking, higher objectives, and new tools.

The enabling resources afforded by the emerging opportunities need to be engaged in coherent sets of activities. The scientific advances resulting from these activities should form building blocks that may be used as the bases for the next set of activities. Research questions need to be posed, and milestones need to be placed as metrics of progress towards fulfilling objectives.

This paper presents a possible agenda for land-surface hydrology research at the beginning of the new millennium. The authors collaborated voluntarily and because no 
institution or agency supported or commissioned the work, this agenda represents a grassroots initiative. The purpose is not to claim the agenda but to open the debate. The topics considered are not all-inclusive. Only land-surface hydrology research is addressed. The prioritization is based exclusively on the collective experience and visions of the authors. The scope is limited but the hope is that, for land-surface hydrology research, this document will serve to add depth and coherence for the rapid growth period which lies ahead. The hope is that other disciplines in hydrology may follow and develop documents describing their challenges in harnessing the excitement and promises and prioritize relevant science questions.

The core of the land-surface hydrology agenda is the science questions posed in Section 3. They define both research thrusts as well as specific milestones. The identification of science questions, and the collection of experiences that allowed their prioritization, are based on existing literature. For the sake of clarity of text, and in order to reduce the need for expanded discussions, the science questions are raised and discussed without specific references. It should be recognized that the discussions are based on the wisdom and publications of the research community at large.

Addressing the science questions necessitates a critical assessment of the available data and modeling needs. In Section 4 the implications of the science questions for research and development of observing systems and models are enumerated.

The authors believe that the discipline is intellectually and technologically ready to take a major step. The moment and the opportunity is reminiscent of the beginnings of the First International Hydrological Decade (IHD), 1965-1974 (UNESCO 1972. 1974ae). During the $1^{\text {st }}$ IHD a series of international workshops on the current and future 
problems in various sub-disciplines of hydrology was organized, and reports of the activities were published by the United Nations Educational, Scientific, and Cultural Organization (UNESCO). The more enduring legacy of the $1^{\text {st }}$ IHD is the international data collection activity which for the first time allowed the world-wide sharing of observations. The $1^{\text {st }}$ IHD had major impacts on the emergence and maturation of the hydrologic sciences.

Focus, cooperation, and communication are crucial to coalesce the many on-going and future activities into progress for the discipline of hydrology. A new international hydrological decade, the $2^{\text {nd }} \mathrm{IHD}$, is now needed. Institutions and agencies at national and international levels need to serve as conduits for exchange of knowledge and data at the global-scale through the $2^{\text {nd }} I H D$. Participating institutions and agencies stand to benefit from the implementation of observing and modeling systems that are possible only with pooled resources. The focus brought about by the $2^{\text {nd }}$ IHD is needed to launch a coherent and vital discipline into the new millennium.

\section{Motivation}

The goals of land-surface hydrology research are the characterization and prediction of flux and storage of water at the Earth's surface and in the coupled zones of the subsurface and the atmosphere. The goals support hazard mitigation (floods, droughts, and landslides), agriculture and food production, human health, municipal and industrial supply, environmental quality, global change and terrestrial ecology research, and a host of other human activities. Water at the surface of the land is both a vital resource and a hazardous force. 
Desertification and drought are problems of global dimension that affect more than 900 million people in 100 countries. Irrigation already accounts for more than $70 \%$ of fresh water withdrawn from lakes, rivers and groundwater aquifers. In dryland regions of the world an estimated 1.2 to 2.5 million hectares require irrigation. It is estimated that $80 \%$ of the additional food supplies required to feed the world's population in the next 30 years depend on irrigation.

Today, about one-third of world's population lives in countries that are experiencing moderate to high water stress, i.e. renewable freshwater availability is below 1700 cubic meters per person per By 2005, it is projected that one-fifth of population does not have access to safe drinking water and more than one-half lack adequate sanitation.

In many respects, despite the emergence of transportation and telecommunication advances, human society still suffers from constraints from water resources. Societies of the new millennium will be as much hydraulic societies as that of early history. Economic growth and social welfare in major urban centers of the semi-arid United States and other mega-cities in the industrialized and industrializing worlds, will still be made more costly by limited water-availability and by hydrometeorological hazards.

Floods and droughts are the leading natural threats to society in many countries (NRC 1996). The impacts of global change brought about by land-use change, desertification, major hydraulic engineering works and anthropogenic greenhouse trace gas emissions will be mostly expressed on or mediated by water at the surface of the Earth. 
Land-surface hydrology is a discipline through which many of the emerging technological advances in remote and in situ monitoring instrumentation, computation, and telecommunication may be brought to bear on dealing with food supply, health, security, and development issues facing the Earth's growing population.

\section{Priority science questions}

\section{a. What are the physical mechanisms and process-pathways by which the coupling} between surface hydrologic systems and the overlying atmosphere modulate regional weather and climate variability?

The exchange of moisture and energy between the soil-vegetation (and snowpack) and the overlying atmospheric boundary layer has significant impacts on the evolution of surface and near-surface atmospheric moisture and temperature states, which in turn largely define regional climate (see Fig. 1). The behavior introduced by the multivariate coupling may also lead to excursions, oscillations, and persistence of hydroclimatological anomalies (e.g. extreme precipitation, droughts, etc.) that are otherwise absent if components of the land-air system are forced in isolation. The incremental contribution of land-atmosphere coupling to regional anomalies such as continental droughts (e.g., 1970's Sahel or 1988 U.S. Midwest) and large-scale flooding precipitation events (e.g., 1993 U.S. Upper Midwest) need to be established and quantified in the context of both observations and models (see also Section 3.f below).

Given the current understanding of surface influence on regional climate dynamics, those states that have long memory or serve to integrate past atmospheric forcing may be used to enhance the prediction skill for regional climates. Soil and vegetation control of available energy partitioning at the land-surface have the effect that 
the short-term evolution of weather events that are affected by surface fluxes (e.g., summer-time precipitating convection) depend on surface hydrologic conditions. Figure 2 shows the gains in forecast skill brought about by the introduction of improved landsurface characterization and initialization in an operational numerical weather prediction model. It should be recognized that the land hydrologic states (e.g., soil moisture and snow) influence surface flux of moisture and energy only under a limited set of conditions that depend on surface properties and atmospheric forcing (see Fig. 3). There are periods at all time-scales (i.e. storm, between storms, and seasonal) and there are geographic regions in which fluxes of moisture and energy are essentially independent of the land-surface moisture state. The regimes and corresponding transitions in which the surface may or may not influence fluxes into the atmosphere at its lower boundary needs to be investigated. The seasonal cycle and interannual variability of each regime need to be established for understanding and predicting variability in regional climates.

A critical problem in coupled land-atmosphere process studies is the requirement to define conceptual frameworks with appropriate system boundaries (see heat and moisture budget example in Fig. 4). The atmospheric boundary layer and the air entrainment processes associated with its large diurnal variations are significant factors in surface energy and mass balance. At larger-scales and over longer periods, the convergence of moisture and static energy across the depth of the troposphere are strong constraints on regional hydroclimatology. Definition of conceptual frameworks, construction of models, and data collection programs that appropriately deal with system boundaries are necessary for successful research on the interactions between the landsurface and its overlying atmosphere. 
b. What are the mechanisms and the time-scales of interactions between the formation of terrain, soils, vegetation ecotones, and hydrologic response?

The development of the pedosphere which determines the dynamic behavior of hydrologic processes and the patterns of regional hydrologic systems in turn is affected by surficial hydrologic and biospheric processes. These mutual interactions between soil and vegetation formation and hydrologic processes occur over a wide range of timescales. The hydraulic properties of soils, including the formation of soil seals and macropores, may change in response to variations in vegetation cover and water balance on the scale of a few seasons and years but soil conditions in environments not disturbed by humans seem to reflect processes on the time-scales of ecosystem change. The development of the soil mantle and distinct horizons within the soil is a process that spans centuries. Often the parameterization of field-scale soil hydraulic behavior is based on inferences about the relations between soil morphology, vegetation type and density, and hydroclimate (see Section 3.d). Investigations leading to a unified understanding of the genesis of soils, vegetation, topography, and hydroclimate are essential.

Similar to soils, but on an even richer spectrum of space and time-scales, vegetation processes and hydrologic flux are substantially linked. A substantial fraction of the hydrologic exchange between the soil and the atmosphere is through vegetation. Conversely, moisture availability is a key factor in the distribution of ecotones. Nonetheless the representation of the role of vegetation in hydrologic models and the consideration of its influence on the hydrologic cycle remain at rudimentary levels. The simplistic representation of vegetation in hydrologic models must be improved through 
more substantial use of the current understanding of plant physiology and variations among species.

In addition to studies of how plant physiology and transpiration responds to moisture availability, investigations into the co-evolution of ecotones and hydroclimate are needed. The amplitude of the components of surface-water balance depend on vegetation function. Furthermore, some interannual variability of hydrologic processes and, on paleo time-scales, shifts in climate are associated with ecotone successions and variations. The nature of these associations needs to be understood, and their geologic and geochemical fingerprints need to be uncovered.

c. Are there critical scales at which spatial variations in surface properties should be explicitly represented in models of land-atmosphere exchange?

Some hydrologic processes such as runoff are significant only because there is heterogeneity in the natural system. Most homogeneous soil textural classes have sorption rates that exceed generally observed rain intensities and they also have sufficient storage to contain an entire rainstorm. Nonetheless, flood runoff occurs widely regardless of prevailing regional soil properties. The intermittent nature of rainstorms and the occurrence of patches of exceptionally low-permeability soil surfaces, rock outcrops, low profile transmissivity, and high topographic convergence zones over the landscape are among the factors that make storm runoff possible. The effects of such heterogeneities occur between the spatial-scales of soil pores and hillslopes. It is not possible to explicitly resolve land-atmosphere exchange models over a wide range of scales. Thus, hydrologic processes such as storm runoff need to be parameterized. Nonetheless, hydrologists need to address important procedural issues regarding development of field- 
scale governing relations based on micro-scale physics (see Section 3.d below) and the statistical characterization of heterogeneity.

For some other hydrologic processes, the effects of heterogeneity are evident at larger-scales that are closer to the scale at which it is feasible to explicitly represent them in numerical models. Variations of snowpack dynamics with topographic aspect, evapotranspiration with gradients in topography, and vegetation, boundary-layer mixing and circulations with surface-cover changes and runoff generation with surface-type and topographic gradients (see Section 3.f), etc. are examples of hydrologic processes that vary on scales which may be feasible to model explicitly. In all hydrologic investigations, it should be natural to identify the critical scales at which spatial variations should be explicitly represented. Such scales, however will vary for each hydrologic process and subject to environmental conditions (see Fig. 5).

d. Under what conditions can effective parameters be used to represent macroscale hydrologic processes and does the upscaling of microscale processes depend on the process or lead to changes in the form of the governing equations?

Due to the complexity of natural hydrologic systems, especially complexities brought about by the presence of multi-scale hetereogeneity (see Section 3.c), many models of field hydrologic processes are essentially based on micro-scale equations with effective parameters. The adequacy of this approach needs to be assessed in the context of the process under consideration. In each case, some effective parameters may be defined. Multi-scale characterization of the variability of parameters based on innovative mathematical statistics may extend their range of applicability. However, there are hydrologic processes which elude upscaling using the effective parameter approach. 
Therefore, procedures for upscaling micro-scale governing equations for such processes need to be established more formally than is done at present. Definition of closure terms for cases where extra field-scale terms are introduced during the process of upscaling may become necessary. Tests for the validation of the field-scale relations need to be designed and implemented.

For example, pedotransfer functions are used to assign hydraulic properties to soils classified into basic soil taxonomic units that are differentiated by parent geology, minerology, texture, bulk density, and organic matter content. In this respect, pedotransfer functions may be considered the first step in scaling hydrologic processes from pore-scale to plot or hillslope scale. Nonetheless, important issues need to be resolved with respect to the design and application of pedotransfer functions. Effects of land-use, vegetation, climate, and topography on pedotransfer predictions need further study. Future research should focus on the estimation of effective hydraulic properties for large areas that contain significant or structured soil heterogeneity. Furthermore, water chemistry (e.g., salinity and ionic composition) influence flow in granular porous media. Methods to include field-scale effects of macropores, layered anisotropy, and preferential flow pathways as well as water chemistry need to be developed. The pedotransfer functions should allow estimation of soil hydraulic properties in the entire root zone (up to 1 or $2 \mathrm{~m}$ deep). Methods for combining multitemporal and multispectral remotesensing with traditional sources of soil taxonomy observations in defining improved pedotransfer functions should be developed.

It should be recognized that the need for upscaling in hydrology is not limited to spatial dimensions. Temporal aggregation is often performed without regard for the 
fundamental scales and the governing relation that implicitly describe the applicable scale. For example, multi-stage evaporation and transitions from flux to ponding surface boundary conditions for infiltration are processes that cannot be aggregated in time without introducing errors (see Fig. 3). Investigations into upscaling hydrologic processes must include both spatial as well as temporal aggregation.

e. Does lateral soil water redistribution significantly affect large-scale soil-vegetationatmosphere exchange processes?

The partitioning of incident precipitation into runoff is dependent on near-surface processes that are significantly influenced by spatial interactions and lateral redistribution of moisture over complex terrain. Runoff-producing zones are limited to areas of low soil permeability, low gradient, and high moisture content. The latter source areas are primarily concentrated around the drainage network, either in convergent topographic regions that receive the gradient-driven lateral water movement in soils, or where the depression of the topographic surface decreases the storage capacity of the soil above the water table (see Fig. 5).

The representation of land-surface hydrologic processes in spatially lumped (e.g., conceptual models used in operational hydrology and flood forecasting) or onedimensional soil hydrology models (e.g., soil-vegetation-atmosphere transfer [SVAT] schemes used in numerical climate and weather forecast models) cannot capture, by construct, these important lateral redistribution processes. Instead, these models rely on the parameterizations to reproduce the results of hydrologic processes over complex terrain by tunable parameters and/or by assigning subgrid heterogeneity to selected parameters (see Section 3.c). Without the lateral redistribution through the regional 
groundwater system, flood runoff from large areas cannot be represented in a realistic manner by these models. For the proper representation of lateral redistribution processes and ground- and surface-water interactions, the scale at which they occur must be considered in developing parameterizations for these models. The scale or range of such scales may depend on climate and topography.

Geochemical tracers are effective tools for mapping subsurface flow systems. Identification of regional groundwater recharge and discharge zones, flow pathway studies, and hydrograph separation techniques require simultaneous hydrologic and geochemical observations. Such observational capabilities, together with the advances computational capability may be used to contruct distributed hydrologic systems based on digital elevation data. These models should be sufficient to make significant gains in determining the role of lateral subsurface redistribution and the role of ground- and surface-water interactions.

f. How can the effects of human activity on hydrologic response be distinguished from natural climate variability in a range of physiographic environments?

Human modification of the environment, such as land-cover change, irrigation, and flow regulation now occur on scales which significantly affect the seasonal and interannual variability of regional hydrologic response (see Figs. 6 and 7). Lowfrequency climate variability and climate change are major contributing factors to the apparent shifts and changes for some of the same processes. The partial contribution of climate variability and human activity need to be separated in the observed record of streamflow, flooding, droughts, and other hydrologic phenomena. 
This requires consideration of methodological issues in both observational and modeling approaches to addressing such phenomena. Robust statistical tests that can quantitatively discriminate the effects of human intervention on inherently noisy hydrologic processes need to be developed. If hydrologic models are used to predict the impact of humans on regional hydrologic processes, the applicability of existing model calibration to the regions where environmental conditions have changed should be evaluated. Issues concerning the impact of model structure on prediction uncertainty, propagation of error within.the model, and, where applicable, the relevance of current calibration parameters for impact studies of changing environments should be assessed.

Hydrologic response, with consequences for regional water resources, need to be assessed using physically-realistic and well-verified hydrologic models that are securely based on field studies of processes. The assessment should also be based on extensive monitoring of networks, and, together with its error analysis, transparently explained to the policy-makers and the public.

\section{Implications for research and development in observing and modeling a. in situ observations}

Concerted initiatives to expand in situ hydrologic observation networks and to archive quality-controlled data from participating nations formed the fundamental objective of the $1^{\text {st }}$ IHD. These objectives need to carry over into the $2^{\text {nd }}$ IHD. There are nonetheless important goals that need to be incorporated into the new set of objectives dealing with in situ observing networks.

Given the multiple uses and users of water resources in modern society, there are often a number of independent agencies and institutions that collect hydrologic data. 
Some of the records span the length of national and institutional boundaries. A consequence of uncoordinated data gathering is that either valuable information is often unknown or limited resources are used to collect redundantly similar type of observations by more than one organization. It is necessary to initiate and implement data-recovery activities to avoid the former problem. In some cases, recovering measurements made over long periods is probably the most cost-effective form of investment that a government or institution could make in environmental monitoring. The World Climate Research Program (WCRP), reports two examples of such initiatives. The Data Rescue (DARE) program in Africa and North and Central America, and the Archival Climate History Survey (ARCHISS) in Europe are designed to rescue and preserve climate data and their associated metadata (WCRP 1997). The $2^{\text {nd }}$ IHD may similarly focus on climate and hydrological data rescue and recovery. The activity may be expanded to include valuable experimental basin records, water quality, soil and land-use surveys, and data from special or non-operational observation missions.

Workshops that focus on a particular data case with the participation of digital archive technologists, institutional representatives, and users need to be sponsored. Incentives for individuals or groups to engage in cost-saving data-recovery activities need to be implemented by funding and mission agencies. The $2^{\text {nd }}$ IHD may serve as the force behind a series of data-recovery initiatives. Furthermore, the $2^{\text {nd }}$ IHD may include the definition of community-wide data archiving and access protocols. Even a distributed information network may be designed to become the dissemination medium for the valuable recovered data (or at least their associated meta-data) to the international community. 
With relatively low costs, existing operational observing networks may be augmented to make valuable new in situ observations. Technological advances in instrumentation allow the addition of new variables to the current suite of standard measurements. For example, addition of soil thermistors to measure soil temperature, inclusion of devices to estimate soil water content, addition of instruments to sense snow depth and properties, and installation of robust surface flux measuring devices, real-time telemetry of acquired observations, etc. to the network of existing surface micrometeorological stations may be technologically feasible and cost-effective. Stream gauging practice can be made more efficient and cheaper through telemetry. Watersurface elevations and gradients can thus be monitored at a greater number of points along the channel and in floodplains and wetlands to record the passage of floodwaves and to provide a means of understanding and predicting inundation processes. Sediment and solute sampling can be automated beyond current levels.

Users and providers of such data need to work together in cost-benefit analysis of the observing systems (e.g., Showstack 1998). Focused workshops may be held as part of the $2^{\text {nd }} \mathrm{IHD}$ to assess the augmentation of existing observing systems to measure new variables. The impact of expanded and extended measuring stations within each network needs to be assessed in terms of both climate monitoring (record continuity) as well as operational (hazard mitigation) benefits. The scientific impact and operational benefits (e.g., avoided disaster costs by improved prediction and warning) should be estimated Documentation of the economic, policy, and scientific value of open-release policies of a few government organizations (e.g., the U.S. Geological Survey and the Brazilian hydrometric agency) may motivate national and international agencies to collaborate. 
There is often the requirement to monitor simultaneously processes that are coupled to hydrologic systems. For example, data on diurnal variations in temperature and humidity profiles of the atmospheric boundary layer are necessary to characterize some aspects of surface water and energy balance (see Fig. 4). Observations leading to the knowledge of the conditions of the troposphere throughout its depth are useful in estimating the entrainment of air into the boundary layer and to evaluate the Earthatmosphere water and energy balance. Other examples include the advantage of simultaneous hydrological and geochemical measurements in characterizing subsurface flow pathways and the use of isotope concentrations to measure long-term sediment loading to channel networks and the exchange of sediment between floodplains and rivers. In all these examples, and for other similar cases, the design and implementation of augmented observing systems needs to be planned so that the acquired observations are suitable for addressing the intended science and application objectives (e.g., the set of measurements allow closure in a energy or mass balance problem).

Data resulting from data-recovery activities, from existing and expanded observing networks, and from other sources need to be archived properly and also made available to the user community. A coherent and organized set of activities dealing specifically with data access for all potential users should be put in place. The $2^{\text {nd }}$ IHD may use its international and multi-institutional position to sponsor the establishment of protocols for systematically linking various hydrologic data archives across the information network. Finally, the establishment of several validation data bases for select basins, and regions with a wide range of climate, vegetation, and seasonal snow conditions under the auspices of international initiatives will substantially facilitate the 
definitive evaluation of new models and techniques that are resulting from rapid advances in the hydrologic sciences (see Fig. 8). These validation data bases could fit within the continental-scale basin experiments of the Global Energy and Water Cycle Experiment (GEWEX) but they would be represent smaller areas with more intensive measurements (WCRP 1997).

\section{b. Remote-sensing}

Remotely-sensed observations of surface conditions with satellites and sub-orbital platforms (e.g., aircraft and balloons) provide synoptic coverage that may lead potentially to shifts in the conceptual frameworks and approaches that have been established for many hydrologic processes. For example, in the atmospheric and oceanic sciences, space-based observations of atmospheric and oceanic transports has led to the reformulation of many fundamental disciplinary ideas. Hydrologic sciences should also recognize the potential impact of remote-sensing observations on the development of the understanding of key hydrologic processes. Remotely-sensed data should be used not only as spatial source of input for applying existing models. In addition, hydrologists should be ready to embrace the opportunity to rethink their framework and models for hydrologic processes based on the spatial, temporal, and multispectral observations with the spatial characteristics of remote-sensing observations. There are several requirements for fulfilling the promise of remote-sensing that challenges the hydrologic community:

1) Classical ideas and associated existing models that are optimized to function with sparse in situ observations of precipitation accumulation, stream discharge, and surface air micrometeorology should be replaced with reformulated hydrologic models that are forced with spectral observations or retrieved fields of spatial data 
(see Section 3.c). Considering the unique advantages of remote-sensing observations, the existing scientific objectives may have to be revised and new questions may have to be posed.

2) Hydrologists need to evolve from passive recipients of limited remote-sensing observations to acting as a unified scientific community that is engaged in supporting the definition, design, and implementation of sub-orbital and space-borne instruments. The key to fulfilling this challenge is a clear demonstration of the positive impact of existing and emerging observation streams on the major scientific objectives and questions.

3) Validation data bases (over regions or basins) consisting of in situ and remote-sensing measurements need to be established so that instruments and retrieval algorithms may be quantitatively and definitively evaluated (see end Section 4.a). Such validation data sets should contain error statistics for the observations included. The validation data bases may cover several locations across diverse climate, vegetation, and other conditions such as seasonal snow cover.

In the current era, a successful remote-sensing mission requires an end-to-end system optimization. The process starts with an analysis of signal-to-noise ratio and other engineering characteristics associated with the instrument mission under consideration to fulfill the science needs under a variety of environmental conditions. Trade-offs between passive and active remote-sensing and synergistic use of multi-spectral (visible, thermal, and microwave) observations should be considered in support of defining the key scientific questions and the attendant measurement requirements. The maximum groundlevel spatial resolution, minimum revisit frequency, maximum tolerable error in 
radiobrightness or reflectivity, maximum off-nadir look angle, and auxiliary data needs, etc. should be included in the scientific/engineering trade-off studies in support of defining/promoting new instruments/missions to address identified science questions. The end-to-end optimization requires a close working relationship between instrument and spacecraft engineers and applications scientists to properly translate the requirements into realistic systems. Such active and interactive dialogue should help reduce the overall definition, development, and implementation cycle resulting in a reduction in the cost of future missions. Simulation of the space-borne system measurements (by numerical simulation and sub-orbital deployment of prototype instruments) may then be used to address important issues such as beamfilling, where the aggregation of contributions from heterogeneous small-scale surface components may yield a measurement that is not representative of the area conditions. Furthermore the transferability of the retrieval algorithms to a wider range of conditions (e.g., vegetation cover, topography, etc.) needs to be quantified and validated. Hydrologic models that are particularly compatible with remote-sensing observations should be designed and implemented to ingest the measurements and produce value-added data products. In the end-to-end optimization, the final stage is the assessment of costs and the impact on improved scientific understanding. The scientific value and benefits derived from improved forecasting in support of hazard mitigation or the ability to solve key agricultural, human health, water resources, and industrial policy issues at the regional, continental, and global levels, should form the basis of mission justification.

It is important to note that such end-to-end optimization is not only for new missions. Elements of the same procedure are applicable, if not necessary, for working 
with existing missions and archived remote-sensing measurements. The same assessment of multi-spectral synergy, retrieval algorithm performance, measurement and retrieval error budget calculations, value-added data production, and data quality control should be made using existing remote-sensing measurements. Furthermore, the same framework in evaluating a measurement technology applies to ground-based weather-sensing radar which provides estimates of precipitation rate at high spatial resolution. Steps need to be taken to assess the retrieval algorithms and to quantitatively establish the impact of radar observations on hydrologic applications, such as flood forecasting with the aid of hydrologic models.

For land-surface hydrologic applications, the existing large amounts of multiangle visible and thermal spectral measurements have been valuable in producing fields of surface incident radiation, surface temperature, spectral albedo, land-cover type, canopy structure features, etc. Unfortunately the atmospheric medium, especially under cloudy conditions, is a strong absorber and reflector of radiation in these ranges of frequencies. The error associated with atmospheric correction under cloudy conditions precludes the use of visible and thermal spectral observations to retrieve surface fields that have relatively small and subtle impacts on the signal. Lower-frequency (longer wavelength) measurements in the microwave region, a spectral region where the atmosphere is relatively more transparent to the surface emission, makes the direct observation of hydrologic fields more feasible. Microwave radiobrightness and back-scatter are useful in mapping precipitation rates because hydrometeors either scatter or emit microwave radiation strongly in several microwave frequencies. Additonally, polarized microwave emissivity is related to important vegetation canopy features and near-surface soil 
wetness. An optimum system would be able to measure microwave radiobrightness in that spectral band which has surface wetness information characteristic of a larger depth of soil below the surface. The system would also measure within spectral bands that are least affected by the atmosphere and moderate vegetation cover. This is possible with low-frequency microwave radiation which is also used for telecommunications. Fortunately a few spectral bands are protected for radio-astronomy. The band centered on $21 \mathrm{~cm}$ wavelength or 1.4 GigaHertz (also known as L-band) is the lowest useful microwave frequency that can yield information on soil dielectric constant, which is related to soil water content (among other factors), down to a few centimeters. Design and deployment of missions to measure Earth emission or reflection of radiation in this frequency is now among the unique opportunities for remote-sensing in hydrology. There still remains some major questions that have yet to be adequately addressed, despite the fact that $\mathrm{L}$-band microwave instruments have been developed and deployed for short periods of time on aircraft and spacecraft (see Fig. 9). The engineering design of large enough space-borne antennae that can collect the relatively weak microwave signal with sufficient fidelity, the design of retrieval algorithms that are robust under a variety of soil morphology, soil texture and vegetation cover conditions, synergy with other spectral measurements, and the trade-offs between active radar and passive radiometry instruments are among the questions to be considered.

There are also other land-surface parameters that can be derived from remotesensing observations for more precise recording of surface characteristics such as topography, vegetation canopy structure, and inundation through side-looking radar and laser altimetry. Surface sediment concentrations in flowing water can also be recorded 
and interpreted to yield vertical concentration profiles or spatial patterns of mixing. Laser and radar altimeters offer the potential for river-stage measurements and assessment of floods.

A successful remote-sensing mission requires end-to-end systems optimization. Phases of this end-to-end optimization for new or existing remote-sensing systems may be carried out in a series of workshops that culminate in comprehensive reports on the existing technological and scientific capacity to form initiatives and missions. The $2^{\text {nd }}$ IHD may serve as the coordinating medium through which the relevant national and international institutions and space agencies may contribute to the major milestones in the development of end-to-end remote-sensing systems for hydrologic data collection.

\section{c. Merging models and observations}

Data assimilation, as the merging of models and data is better known, is the application of the set of mathematical techniques that provides physically consistent estimates of spatially distributed environmental variables. The estimates are often based on merging scattered and/or indirect remote-sensed measurements of states and parameters with dynamic models that impose physical consistency constraints. Those variables whose spectral signatures are measured by satellite sensors belong to physical systems that contain strong constraints on the dynamics and covariability of the variables under consideration. Therefore, geophysical inversion of satellite measurements may gainfully rely on the constraints imposed by the physical system in order to infer useful $a$ priori information on the variables.

Data assimilation for the purpose of geophysical inversion is particularly applicable to hydrology for several reasons. First, hydrologic systems contain 
components with a wide range of time-scales. For example, vegetation canopy structure varies on the scales of seasons, while surface temperature and moisture vary with the diurnal period. For example, the inversion algorithms which need to simultaneously estimate canopy interference and surface emission may make simultaneous inversion of multiple-day measurements but keep the canopy parameter as temporally invariant over a given period. The degrees of freedom associated with this inversion example are thus reduced significantly. A second incentive for the use of data assimilation in hydrologic remote-sensing is that auxiliary data from in situ observations may often provide important information on factors contributing to the remotely-sensed signal. For example, soil texture surveys, surface micrometeorology, etc. may be merged with remote-sensing data in the context of numerical models. Third, the radiobrightness or reflectivity measured by current satellites is limited to spectral ranges that have penetration depths into the soil or water of fewer than several centimeters. Any inference of subsurface conditions that are of interest to hydrology need to be made using models and their implicit physical relations that propagate information from the remotely-sensed domain to regions beyond the reach of the measured spectral signal. Fourth, hydrologic applications of remote-sensing often require simultaneous estimates of several variables which may be derived from multi-spectral and multi-sensor measurements. Data assimilation methods could be used to incorporate and relate the complementary features of diverse remotely-sensed and in situ measurements. Finally, the data assimilation framework may be used to analyze the value of various data streams in constraining uncertainty associated with modeling or estimation at different scales and for different processes. 
The application of data assimilation techniques to hydrologic remote-sensing require significant development and maturation milestones. Assimilation system models which constitute the physical constraints need to be developed. Classical hydrologic models that have been optimized for use with sparse in situ observations such as precipitation accumulation and streamflow are inadequate for extension to work with remote-sensing data (see Section 4.b). Models and model components for land-surface processes need to be developed following criteria for parsimony and observability. Procedures for their rigorous validation should be defined. It should be recognized that land-surface hydrology models for simulation and for assimilation applications may have significantly different requirements/characteristics.

Techniques of mathematical statistics that can efficiently capture the multiscale variations of spatial fields should be considered for the integration of multi-resolution observations and the representation of heterogeneous conditions. Computationally efficient sequential assimilation techniques that are capable of adequately characterizing multiscale temporal dynamics of states in the data assimilation context should also be investigated for applications to hydrologic remote-sensing.

Finally, the importance of modeling studies that do not employ data assimilation must be also stressed. Such free-running models (e.g., coupled land-atmosphere models are integrated in climate mode) have prognostic variables that vary in response to the modeled physics and thereby allow sensitivity studies that help isolate and characterize physical controls over hydrological variability. Realistic model physics and coupling behavior is, of course, critical to the believability such sensitivity analyses. Many of the 
priority science questions outlined in Section 3 relate to increasing the realism of hydrological models.

\section{Summary}

A call to initiate the $2^{\text {nd }}$ International Hydrological Decade (IHD) is made. The priority science questions that should drive the international activity are presented. The possible agenda is intended to open the debate for the development of a set of objectives for land-surface hydrology research in the first decade of the new millennium. These years will be marked by technological advances and opportunities that enable major scientific advances for the discipline.

Representative science questions outlined here necessitate improvements in observations and modeling efforts. The criteria for the extension and expansion of in situ observing systems are defined. The emergence of satellite remote-sensing as a tool for collecting measurements with unprecedented spatial and temporal coverage is probably the most important enabling measurement technology. The advances in observational and computational technologies has and will further enable the operational application of data assimilation methodologies for inferring information from indirect measurements or from sparsely observed fields.

The hydrologic science of the $2^{\text {nd }}$ IHD is substantially different from the discipline that emerged even at the end of the $1^{\text {st }}$ IHD. It is now widely recognized that major science questions in land-surface hydrology may be approached only by representing adequately the coupling of surface hydrologic processes with relevant portions of the subsurface and overlying atmosphere. This realization is reflected in the priority science questions of Section 3 as well and it has important implications for both modeling and 
observing strategies. A second distinguishing feature of modern land-surface hydrology research that now stands in contrast to that of the $1^{\text {st }}$ IHD is that the global or large-scale approach is generally the starting point, and the challenge is to characterize regional or smaller-scale features. The river basin is no longer the exclusive unit of study. Although important questions remain about streamflow generation, flood hazard, floodplain habitability, and riverborne material fluxes, the human activities, research questions, and observing systems associated with land-surface hydrology are now coupled to biospheric and atmospheric processes not all of which are confined to river basins.

The burden of making the agreements and protocols that will launch the $2^{\text {nd }}$ IHD falls on national and international institutions and agencies that deal with scientific research and cooperation, water resources, and environmental natural hazards. The possible agenda for land-surface hydrology research reported here should signify the vision and readiness of the research community to take the initiative for advancing the discipline based on emerging technological and computational advances, scientific innovations, and national and international cooperations. The discipline can and should lead in developing the scientific knowledge required to address contemporary environmental issues such as food security, human health, and economic development facing the global community in the $21^{\text {st }}$ Century. Hydrologists have a long history of such contributions, and now have the necessary technical and scientific tools to respond to even greater challenges. 


\section{References}

Betts, A. K., and J. H. Ball, 1995: The FIFE surface diurnal cycle climate, J: of Geophy. Res., 100(D12), 25,679-25,693.

Dirmeyer, P. A., 1997: The Global Soil Wetness Project (GSWP)-Initial resutls, GEWEX News, 7(2), 3-6.

Jackson, T. J., (1997): Southern Great Plains 1997 (SGP97) Hydrology Experiment Plan, Hydrology Laboratory, Agricultural Research Service, U.S. Department of Agriculture, 186 pages (http:// hydrolab.arsusda.gov/sgp97/documents.html).

National Research Council (NRC), 1991: Opportunities in the Hydrologic Sciences, National Academy Press, Washington, D.C.

National Research Council (NRC), 1996: Assessment of Hydrologic and Hydrometeorological Operations and Services, National Academy Press, Washington, D.C.

Salvucci, G. D., 1997: Soil and moisture independent estimation of stage-two evaporation from potential evaporation and albedo or surface temperature, Water Resour. Res., 33(1), 111-122.

Showstack, R., 1998: Real-time monitoring and warning for natural hazards can provide real-time benefits, EOS, 79(28), 329-333.

United Nations Educational, Scientific, and Cultural Organization (UNESCO), 1972: Status and Trends of Research in Hydrology: A Contribution to the International Hydrological Decade, UNESCO, Paris.

United Nations Educational, Scientific, and Cultural Organization (UNESCO), 1974a: Records of the International Conference on the Results of the International 
Hydrological Decade and on Future Programmes in Hydrology: I. Final Report, UNESCO, Paris.

United Nations Educational, Scientific, and Cultural Organization (UNESCO), 1974b:

Records of the International Conference on the Results of the International Hydrological Decade and on Future Programmes in Hydrology: II. Reports of International Governmental and Non-Governmental Organizations on their Contributions to the Programme of the Decade, UNESCO, Paris.

United Nations Educational, Scientific, and Cultural Organization (UNESCO), 1974c: Records of the International Conference on the Results of the International Hydrological Decade and on Future Programmes in Hydrology: III. Technical Reports of the Working Groups of the Co-ordinating Council of the International Hydrological Decade, UNESCO, Paris:

United Nations Educational, Scientific, and Cultural Organization (UNESCO), 1974d: Records of the International Conference on the Results of the International Hydrological Decade and on Future Programmes in Hydrology: IV. Technical Reports of the Working Groups of the Co-ordinating Council of the International Hydrological Decade, UNESCO, Paris.

United Nations Educational, Scientific, and Cultural Organization (UNESCO), 1974e: Records of the International Conference on the Results of the International Hydrological Decade and on Future Programmes in Hydrology: V. Technical Reports on Selected Scientific Activities Related to the IHD Programme, UNESCO, Paris. 
Western, A. W. and R. B. Grayson, 1998: The Tarrawarra data set: Soil moisture patterns, soil characteristics, and hydrological flux measurements, Water Resour. Res., 34(10), 2765-2768.

World Climate Research Programme (WCRP), 1997: Seventh Planning Meeting on World Climate Programme-Water, Koblenz, Germany, 13-16 May, 1997, Final Report, WCASP-45, WMO/TD-No. 854, Geneva. 
FIG. 1 This figures demonstrate both the impact of soil moisture on the numerical forecasting of the extreme events and the notion that surface soil moisture is equivalent in importance to sea surface temperature (SST) as boundary conditions for the climatic system. In panel (a) the observed precipitation over the continental U.S. for summers containing the extreme 1988 drought and 1993 flood events are presented as a difference field. In panels (b), (c), and (d) general circulation model results for the same differences between rainfall during the 1993 flood and 1988 drought events are shown. In panel (d) observed SSTs are used as boundary condition for the simulation in conjunction with estimated soil moisture climatology. In panel (c) estimates of soil moisture for the particular time-period are used in conjunction with SST climatology. In panel (b) both SSTs and soil moisture fields are either observed or estimated for the specific period of simulation. It is evident that precipitation extremes over the U.S. are more strongly affected by soil moisture fields than SSTs. which are currently the principal fields used to extend forecast lead-times (personal communication, M. Suarez, S. Schubert and A. Chang). 
FIG. 2 The proper treatment of land-surface hydrology is critical for accurate numerical simulations of weather and climate. One practical benefit of improved land-surface modeling is improved short-term weather prediction. The figure, above shows threat scores (a measure of forecast skill) for 36-hour forecasts of 24-hour accumulated precipitation as a function of precipitation threshold. The bottom curve shows the relationship obtained when the prediction system uses a standard bucket model initialized with climatological soil moisture values. The upper curve shows the relationship obtained when the bucket model is replaced by a more sophisticated land-surface scheme and the soil moisture is more realistically initialized from reanalysis data. The combination of improved model physics and improved initial conditions for soil moisture has led to significantly improved weather prediction. The improvement seen here is of the same order as that obtained from doubling the resolution of the atmospheric model. (Ken Mitchell, personal communication) 
FIG. 3 Evaporation following rain storms and soil-wetting proceed through several stages. In the first stage, although soil moisture is steadily depleted by evaporation (equal to the so-called potential evaporation, $e_{p}$ ), the rate of evaporation is limited only by available energy to vaporize liquid soil water and it is essentially independent of soil moisture content. During the early period of the day or across high-latitude regions where available energy may be the limiting factor, this first phase may extend up to the next wetting event. Similarly in climates with frequent wetting events, the first stage may dominate much of the time. During the second stage of evaporation, lower-levels of soil moisture limit the movement of water in the soil to supply evaporation at the surface. The tránsition from the first to the second stage occurs at the time-to-drying $\left(\mathrm{t}_{\mathrm{d}}\right)$ which depends on soil texture and climate. The figure shows field experiment observations by R. D. Jackson and the applicability of a model of the process by Salvucci (1997). The soil drying effect and the time-to-drying are evident in the albedo observations (lower figure). During this phase of evaporation soil moisture exerts strong influence on latent heat flux, surface energy balance, ground temperature, and the near-surface atmosphere states. In a third stage (not evident in this experiment), the evaporation rate is dominated by vapor flow driven by thermal gradients within the soil column. The influence of soil texture, vegetation, and atmospheric forcing on the timing of the transitions between evaporation regimes, and the effects of spatial and temporal aggregation on modeling the phenomena are not yet well-established. 
FIG. 4 Surface water and energy budgets are strongly coupled to the mixed atmospheric layer above the surface. In some applications it may be important to include the mixedlayer water and energy budgets together with that of the surface. This is effectively redefining the control volume or the system boundaries for budget calculations. In the top panels the profiles of specific humidity $(q)$ and potential temperature $(\theta)$ are shown conceptually for two time periods during the growth phase of the mixed-layer. In (a) the results of surface input into the mixed-layer are considered in isolation. Evaporation $(E)$ and sensible heat flux $(H)$ contribute to increase the $q$ and $\theta$ of the mixed-layer with height $(h)$. If the $h$ is fixed, the profiles of the variables at the new time follow the dashed lines. However, the $h$ grows during the time-period in response to thermals originating from near the surface. When the mixed-layer grows to the new height $(h+d h)$, dry- and warm-air is entrained into the mixed-layer as depicted in (b). This growth in $h$ contributes dry air to the mixed-layer partially counteracting the moistening-effect of surface evaporation. In contrast, the entrainment of air with higher $\theta$ from aloft, similar to surface sensible heat flux, contributes to increase the mixed-layer $\theta$. As a result, often times the diurnal-range of $q$ in the mixed-layer is small and the diurnal-range of $\theta$ is large. This is evident in the figure in the lower panel where averages of diurnal coevolution of the two variables are plotted for a set of days with different mean soil moisture (SM) but similar net radiation conditions across the FIFE field experiment site in Kansas (from Betts and Ball 1995). The diurnal range of $q$ is small and the curvature is reminiscent of the early-day evaporation input into a shallow mixed-layer and decrease during the latter part of the day when there is more rapid growth of the mixed-layer into drier portions of the atmosphere. The potential temperature, $\theta$, has a larger diurnal amplitude. The amplitude of the diurnal cycle in $\theta$ is larger for days with drier landsurface conditions when the surface sensible heat flux and growth of the mixed-layer due to thermals originating from the near-surface are dominant factors. Since the surface turbulent fluxes ( $E$ and $H$ ) are driven by the gradient between the surface moisture and temperature states and those in the near-surface atmosphere, the coupled evolution of these states at the land-surface and within the mixed-layer may contain important feedback phenomena. 
FIG. 5 High-resolution in situ observations of the soil moisture field in the small $(0.1$ $\mathrm{km}^{2}$ ) Tarrawarra experimental catchment, southeastern Australia demonstrates the role of competing hydrologic processes in defining spatial structures in the soil moisture field (Western and Grayson 1998). The top panel shows the volumetric moisture content within the top $30 \mathrm{~cm}$ of soil during a typical wet-season day (September 27, 1995). In this case soil moisture pattern is organized by terrain elevation. The wetter zones follow elevation contours and drainage depressions. High hydraulic conductivity of moist soils allows significant redistribution along topographic gradient. During a typical day in the dry-season (22 February, 1996 conditions shown in the bottom panel), there is no discerned correspondence between topography and soil moisture. Dry soil moisture has lower hydraulic conductivity and lateral redistribution is less dominant as a factor in organizing soil moisture patterns. The random spatial variability of soil texture may be a more critical factor in explaining any spatial variability in the soil moisture field. Lateral redistribution in the saturated and unsaturated zones, ground- and surface-water interaction, evapotranspiration, macro-pore flow, and soil texture heterogeneity are among the competing factors that influence the spatial organization of surface soil moisture fields. Detailed understanding of these processes and developing parsimonious characterizations of them for inclusion in coarse-resolution models remain important challenges in land-surface hydrology. 
FIG. 6 This figure shows that the scale of human impacts on hydrologic systems and possibly regional climates. The Caspian sea is the largest lake in the world and it is fed principally by Volga and Ural rivers. Around mid-Century the narrow passage between the Caspian and Kara-Bogaz Bay (see map) was sealed. The reduction in the evaporating surface of the led to rapid rise in the Caspian sea-level (curve 1) although the river inflow into the lake (curve 3 ) has fluctuations around a stationary mean. Many coastal cities were inundated following the $3 \mathrm{~m}$ of water-level increase. Curve 2 is the water-level in the Kara-Bogaz Bay and it show precipitous decrease following the closing of the passage and cessation of major inputs. Eventually evaporation from the area covering the Kára-Bogaz Bay, a major supply of local atmospheric moisture for this inner-continental and dry central Asia region, diminished. The impacts of these large environmental changes on regional climates is largely unknown. 
FIG. 7 Human land-use practices can lead to significant changes in large-scale hydrological fluxes. The figure on the left shows a Landsat image of the Imperial Valley, on the border between California and Mexico. Red indicates the presence of vegetation. The sharp southern border of the red region sits right on the California Mexico border and thus reflects different land-use practices in the two countries. Evaporation must be significantly higher north of the border. The figure on the right shows the extent of irrigation in the U.S.. The patterns suggest a large-scale human-induced increase in evaporation from the land-surface, particularly in the arid west. The effects of this increase on large-scale weather patterns are unknown. 
FIG. 8 The importance of high quality in-situ data to hydrological modeling is indicated in the above plot. Each of a number of different river basins is represented in the plot by two points: a circle for 1987 data, and a triangle for 1988 data. The abscissa represents "model error", i.e., it represents the average runoff generated for the basin by nine landsurface parameterizations (LSPs) minus the observed runoff there. The LSPs were forced with observed precipitation, radiation and other atmospheric variables for 1987-1988 as part of the Global Soil Wetness Project (GSWP). The ordinate shows the density of raingauges within the basin, a measure of the accuracy of the precipitation forcing used by the LSPs. The salient feature of the plot is the significant reduction in model error as the density of rain-gauges increases. This suggests that much of the overall error in model runoff predictions may not related to flaws in the model parameterizations but to an inadequate coverage of rain-gauges (courtesy of T. Oki and cited in Dirmeyer 1997). 
FIG. 9 Remote-sensing technology can transcend many of the economical and logistical problems that limit the effectiveness of in situ measurement systems. An example of the potential use of remote-sensing for hydrological research is shown above. During the Southern Great Plains 1997 (SGP97) Hydrology Experiment, the L-band Electronically Scanned Thinned Array Radiometer (ESTAR) was deployed on a low-flying aircraft (Jackson 1997). Daily mapping of surface brightness temperature over an area greater than $10,000 \mathrm{~km}^{2}$ and a period on the order of a month was conducted. Sample images from two consecutive days in June show a large drop in brightness temperature at the top of the mapped region in response to the significant rainfall event that covered the area in the interim between samplings. Surface soil moisture fields may be inferred from such remote-sensing observations with good accuracy. High costs would prohibit the estimation of spatial fields of soil moisture across large-areas using in situ probes. 


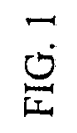

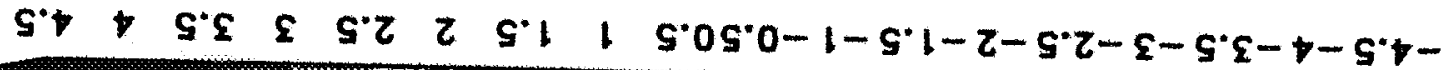

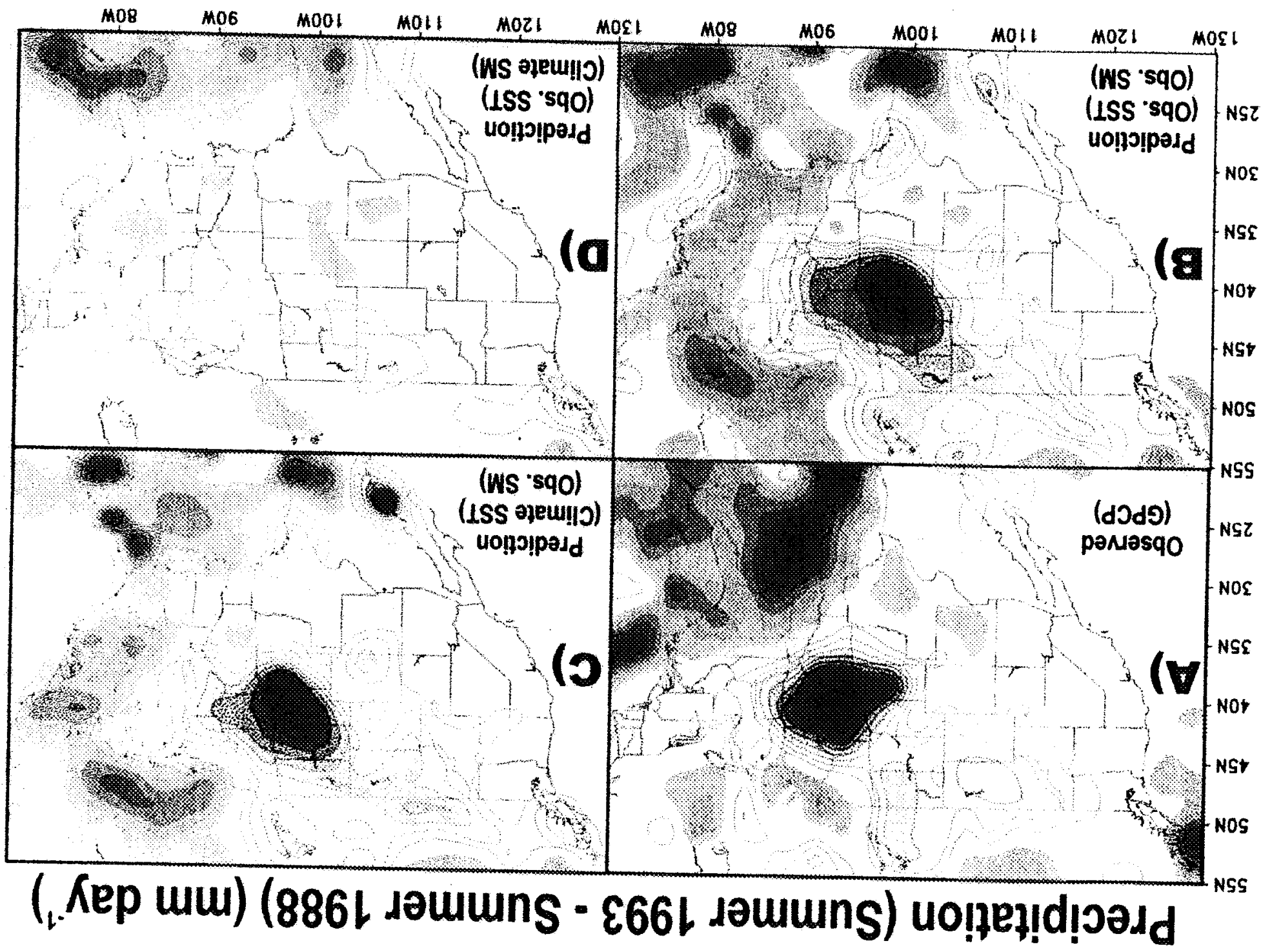


FIG. 2

\section{PRECIPITATION FORECAST SKILL (WARM SEASON THREAT SCORE - 36 HOUR)}

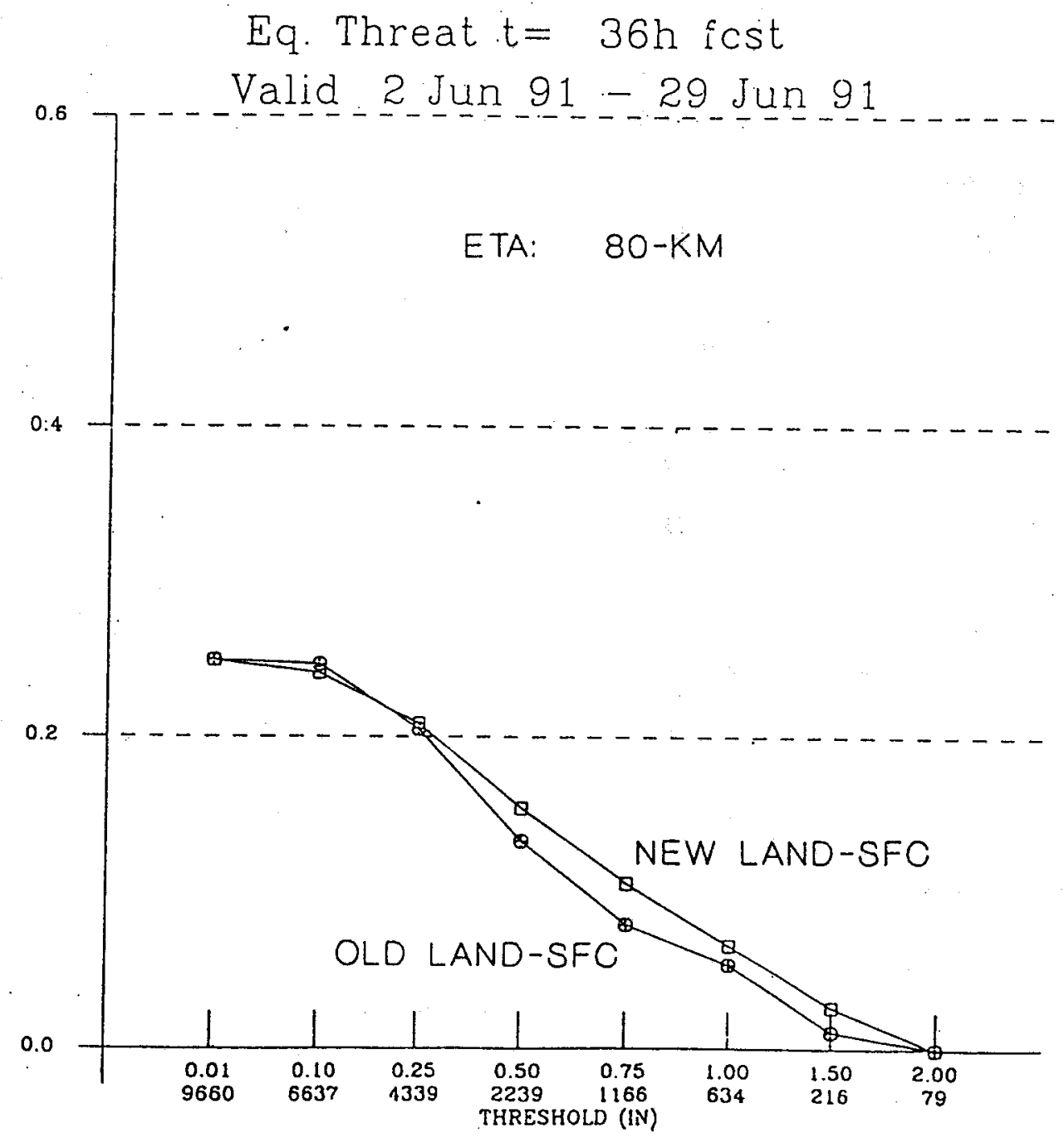


FIG. 3
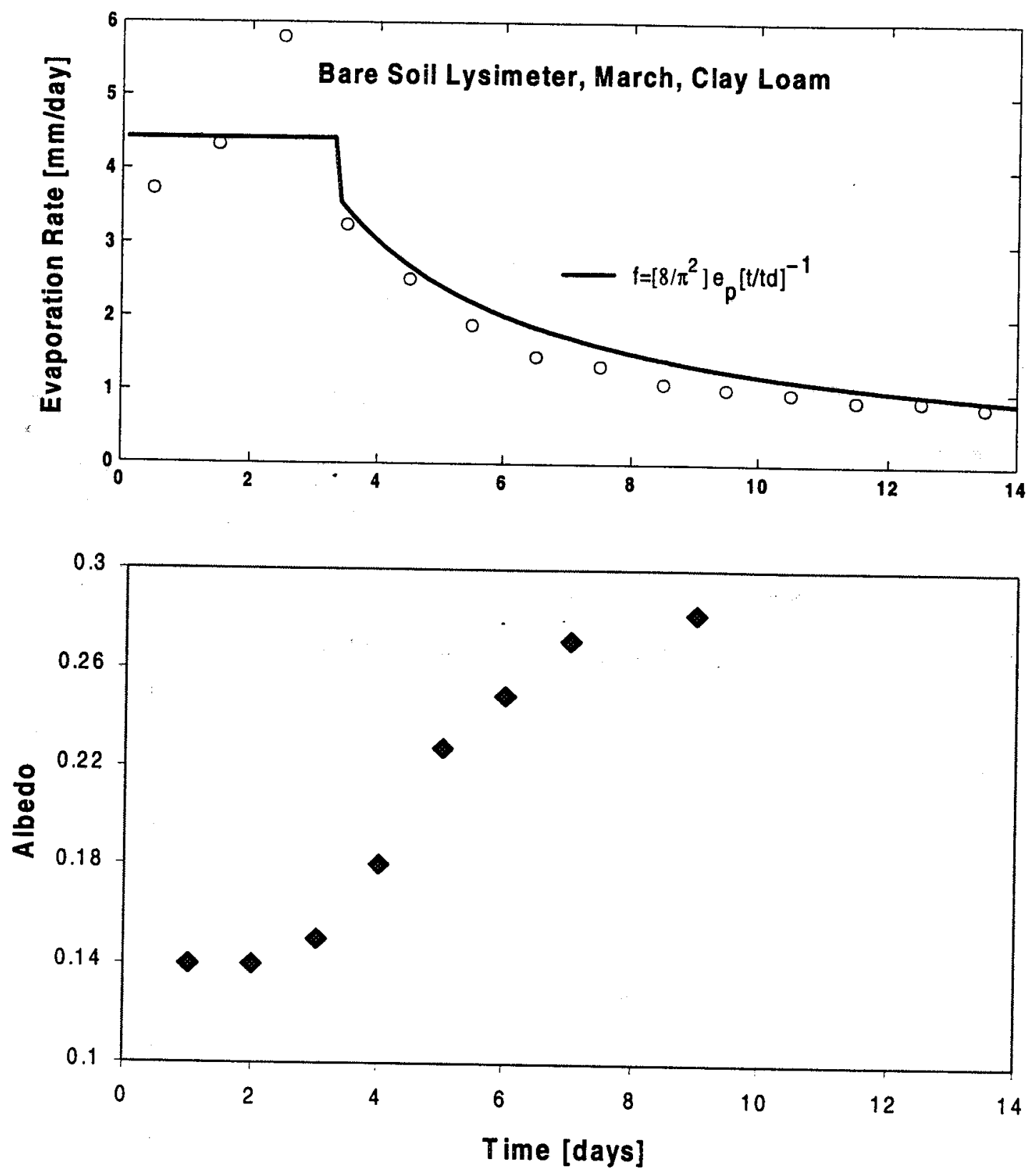
ESTAR Imuge of SOP

June 25, 1907 (Ave. Height 25,000 (t)

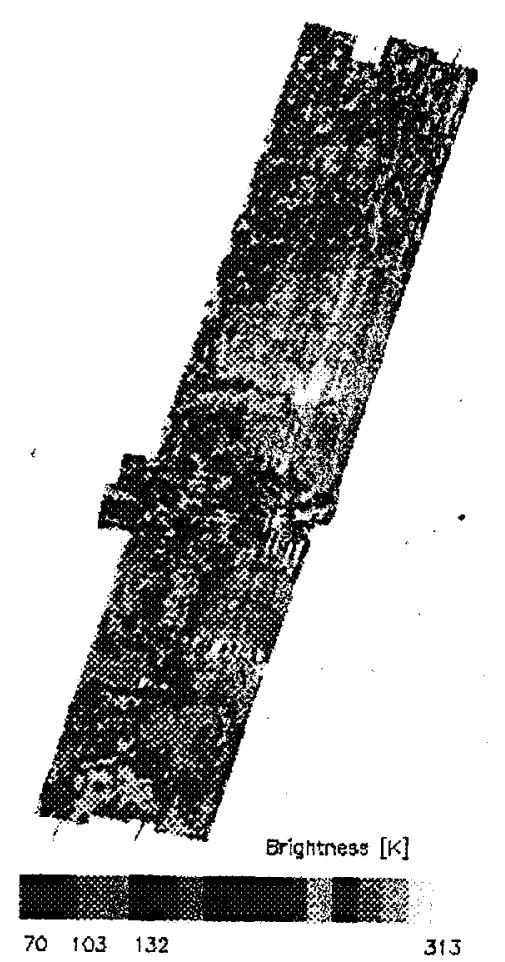

June 26, 1997 (Ave. Height 25,000 it)

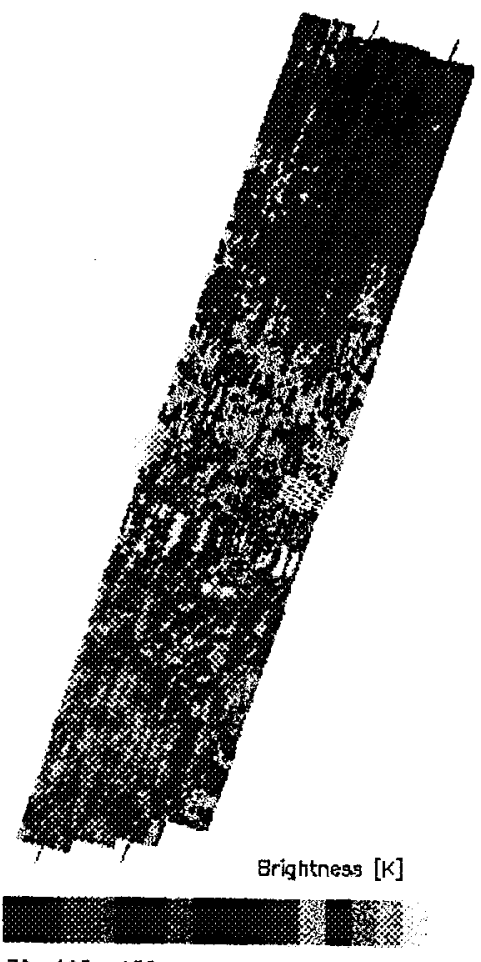

313 
"Agenda for Land-Surface Hydrology Research and a Call for the Second International Hydrological Decade", by D. Entekhabi, G. Asrar, A. Betts, K. Beven, R. Bras, C. Duffy, T. Dunne, R. Koster, D. Lettenmaier, D. McLaughlin, J. Shuttleworth, M. van Genuchten, M. Wei, and E. Wood.

\section{Statement of Significance}

QUESTION: Over the last several decades, hydrology has gained credibility as a full earth system science. At this point in the science's evolution, two important questions can be asked. First, what are the main challenges to be faced in land surface hydrology in the coming decades? Second, how can we work together to meet these challenges?

APPROACH: A group of hydrologists gathered together to discuss these questions. Their discussions and conclusions form the body of the report.

SIGNIFICANCE AND IMPLICATIONS OF FINDINGS: Several important hydrological problems were identified, and in situ data retrieval, remote sensing technology development, and data assimilation were highlighted as means to attack these problems. The paper calls for the initiation of the "2nd International Hydrological Decade", a vehicle for facilitating international data transfer and coordinated hydrological activities.

\section{RELATIONSHIP TO MTPE SCIENCE PLAN}

The land surface hydrology issues addressed here relate to MTPE emphases on (1) seasonal-to-interannual climate prediction, (2) changes in long term climate, and (3) landcover and land use change. 
